\title{
MHD-Conjugate Free Convection from an Isothermal Horizontal Circular Cylinder with Joule Heating and Heat Generation
}

\author{
NHM. A. Azim ${ }^{1}$ and M. K. Chowdhury ${ }^{2}$ \\ ${ }^{1}$ School of Business Studies, Southeast University, House-64, Road-18, Block-B, Banani, Dhaka 1213, Bangladesh \\ ${ }^{2}$ Department of Mathematics, Bangladesh University of Engineering and Technology, Dhaka 1000, Bangladesh \\ Correspondence should be addressed to NHM. A. Azim; nhmarif1@gmail.com
}

Received 31 March 2013; Revised 27 July 2013; Accepted 15 August 2013

Academic Editor: Ivan D. Rukhlenko

Copyright (C) 2013 NHM. A. Azim and M. K. Chowdhury. This is an open access article distributed under the Creative Commons Attribution License, which permits unrestricted use, distribution, and reproduction in any medium, provided the original work is properly cited.

\begin{abstract}
The present work is devoted to the numerical study of laminar magnetohydrodynamic (MHD) conjugate natural convection flow from a horizontal circular cylinder taking into account Joule heating and internal heat generation. The governing equations and the associated boundary conditions for this analysis are made nondimensional forms using a set of dimensionless variables. Thus, the nondimensional governing equations are solved numerically using finite difference method with Keller box scheme. Numerical outcomes are found for different values of the magnetic parameter, conjugate conduction parameter, Prandtl number, Joule heating parameter, and heat generation parameter for the velocity and the temperature within the boundary layer as well as the skin friction coefficients and the rate of heat transfer along the surface. It is found that the skin friction increases, and heat transfer rate decreases for escalating value of Joule heating parameter and heat generation parameter. Results are presented graphically with detailed discussion.
\end{abstract}

\section{Introduction}

Two-dimensional laminar natural convection from a horizontal cylinder under various surface boundary conditions such as isothermal, uniform heat flux, and mixed boundary conditions was investigated by several researchers employing the different numerical techniques. For example, Merkin [1] analysed the free convection boundary layer on an isothermal horizontal cylinder. Kuehn and Goldstein [2] determined numerical solution for the Navier-Stokes equations for laminar natural convection about a horizontal isothermal circular cylinder. They obtained the solutions of the NavierStokes and energy equations for natural-convection heat transfer from a horizontal isothermal cylinder and found that boundary layer conditions reached at the lower portion of the cylinder when the Rayleigh number becomes very large. Wang et al. [3] investigated numerical computation of natural convection flow about a horizontal cylinder using splines. They reported some new computations at very high Rayleigh numbers which indicate the existence of attached "separation" vortices in the downstream plume region.

The combined effect of conduction and free convection which is known as conjugate free convection has a significant importance in many practical applications. Gdalevich and Fertman [4] investigated conjugate problems of natural convection. Miyamoto et al. [5] investigated the effects of axial heat conduction in a vertical flat plate on free convection heat transfer. They discovered that axial heat conduction in the flat plate significantly affects the temperature distribution within the boundary layer. Pozzi and Lupo [6] investigated the entire thermofluid-dynamic (TFD) field resulting from the coupling of natural convection along the surface of the flat plate and conduction inside a heated flat plate by two expansions: regular series and asymptotic expansions. Kimura and Pop [7] analysed conjugate natural convection from a horizontal circular cylinder. The results obtained by Kimura and Pop [7] 
showed that the ratio of thermal conductivities of the solid wall to that of fluid within the boundary layer substantially influenced the flow and heat transfer characteristics.

On the other hand, the electromagnetic fields are used to control the heat transfer as in the convection flows and aerodynamic heating and heat is also produced by electromagnetic fields such as MHD generators and pumps. A substantial quantity of research has been done in the presence of electromagnetic field of the flow and heat transfer characteristics over a variety of geometries. For example, Wilks [8] studied MHD-free convection about a semi-infinite vertical plate in a strong cross field. Hossain [9] studied the effects of viscous dissipation and Joule heating on MHDfree convection flow with variable plate temperature. He concluded that dissipative heat reduces the velocity field more in the lower Prandtl number fluid than that of the higher Prandtl number. The author also revealed that the dissipative heat reduced temperature field faster in the higher Prandtl number than that in lower Prandtl number fluid. Aldoss et al. [10] analysed MHD mixed convection from a horizontal circular cylinder. They found that the increase in the magnetic field leads to a decrease in the flow field, a rise in the temperature values of the flow field, and a decrease in the local wall shear stress and local Nusselt number. The combined effect of viscous dissipation and Joule heating on MHD forced convection over a nonisothermal horizontal cylinder embedded in a fluid saturated porous medium was studied by El-Amin [11].

Many practical heat transfer applications involve the conversion of some form of mechanical, electrical, nuclear, or chemical energy to thermal energy in the medium. Such mediums are said to involve internal heat generation. For example, a large amount of heat is generated in the fuel elements from atomic reactors as a result of atomic fission that serves as the heat source for the nuclear power plants. The heat generated in the sun as a result of fusion of hydrogen into helium makes the sun a large nuclear reactor that supplies heat to the earth. Possible heat generation effects may modify temperature distribution and, therefore, the particle deposition rate. The heat transfer in a laminar boundary layer flow of a viscous fluid over a linearly stretching continuous surface with viscous dissipation/frictional heating and internal heat generation was analysed by Vajravelu and Hadjinicolaou [12]. They considered the volumetric rate of heat generation, $q^{\prime \prime \prime}\left[\mathrm{W} / \mathrm{m}^{3}\right]$, as $q^{\prime \prime \prime}=Q_{0}\left(T_{f}-T_{\infty}\right)$, for $T_{f} \geq T_{\infty}$ and $q^{\prime \prime \prime}=0$, for $T_{f}<T_{\infty}$, where $Q_{0}$ is the heat generation constant. The effects of heat generation/absorption and the thermophoresis on hydromagnetic flow with heat and mass transfer over a flat plate were investigated by Chamkha and Camille [13]. Méndez and Treviño [14] studied the conjugate-natural convection heat transfer along a thin vertical plate with nonuniform internal heat generation. Natural convection flow from an isothermal horizontal circular cylinder in the presence of heat generation was studied by Molla et al. [15]. They found that the skin-friction coefficient increases and the Nusselt number decreases for increasing values of the heat generation parameters. Mamun et al. [16] investigated MHD-conjugate heat transfer analysis for a vertical flat plate in presence of viscous dissipation and heat generation. Recently, Azim et al. [17] analysed viscous Joule heating MHD-conjugate heat transfer for a vertical flat plate in the presence of heat generation.

In this study, MHD-conjugate natural convection flow from a horizontal circular cylinder with Joule heating in the presence of heat generation is considered. To the best of our knowledge, this problem has not been considered before. The governing equations are transformed into a nondimensional form, and the resulting nonlinear partial differential equations are solved numerically using the implicit finite difference method together with the Keller box technique $[18,19]$.

\section{Mathematical Analysis}

Let us consider a steady, laminar, two-dimensional, incompressible, electrically conducting natural convection flow from an isothermal horizontal circular cylinder of radius $a$ placed on a fluid of uniform temperature $T_{\infty}$ (see Figure 1). The cylinder has a heated core region of temperature $T_{b}$ and the normal distance from the inner surface to the outer surface is $b$ with $T_{b}>T_{\infty}$. A uniform magnetic field having strength $B_{0}$ is acting normal at the cylinder surface. It is assumed that the fluid properties are constant, and the induced magnetic field is ignored. In addition, it is also considered that the boundary layer thickness is very small compared with the external radius " $a$ " of the cylinder. The $\bar{x}$-axis is taken along the circumference of the cylinder measured from the lower stagnation point, and the $\bar{y}$-axis is taken normal to the surface. Under the balance laws of mass, momentum, and energy and with the help of Boussinesq approximation to the body force term in the momentum equation, the equations governing this boundary layer natural convection flow can be written as follows:

$$
\begin{gathered}
\frac{\partial \bar{u}}{\partial \bar{x}}+\frac{\partial \bar{v}}{\partial \bar{y}}=0 \\
\bar{u} \frac{\partial \bar{u}}{\partial \bar{x}}+\bar{v} \frac{\partial \bar{u}}{\partial \bar{y}}=\nu \frac{\partial^{2} \bar{u}}{\partial \bar{y}^{2}}+g \beta\left(T_{f}-T_{\infty}\right) \sin \left(\frac{\bar{x}}{a}\right)-\frac{\sigma B_{0}{ }^{2} \bar{u}}{\rho} \\
\bar{u} \frac{\partial T_{f}}{\partial \bar{x}}+\bar{v} \frac{\partial T_{f}}{\partial \bar{y}}=\frac{\kappa}{\rho c_{p}} \frac{\partial^{2} T_{f}}{\partial \bar{y}^{2}}+\frac{\sigma B_{0}{ }^{2} \bar{u}^{2}}{\rho c_{p}}+\frac{Q_{0}}{\rho c_{p}}\left(T_{f}-T_{\infty}\right)
\end{gathered}
$$

The appropriate boundary conditions $[7,20]$ of the system are

$$
\begin{gathered}
\bar{u}=\bar{v}=0, \quad T_{f}=T(\bar{x}, 0), \\
\frac{\partial T_{f}}{\partial \bar{y}}=\frac{\kappa_{s}}{b \kappa_{f}}\left(T_{f}-T_{b}\right) \quad \text { on } \bar{y}=0, x>0, \\
\bar{u} \longrightarrow 0, \quad T_{f} \longrightarrow T_{\infty} \quad \text { as } \bar{y} \longrightarrow \infty, \bar{x}>0 .
\end{gathered}
$$

To transform the governing equations (1)-(3) and the boundary conditions $(4)$ from the $(\bar{x}, \bar{y})$ coordinates to the dimensionless coordinates $(x, y)$ for the free convection dominated 


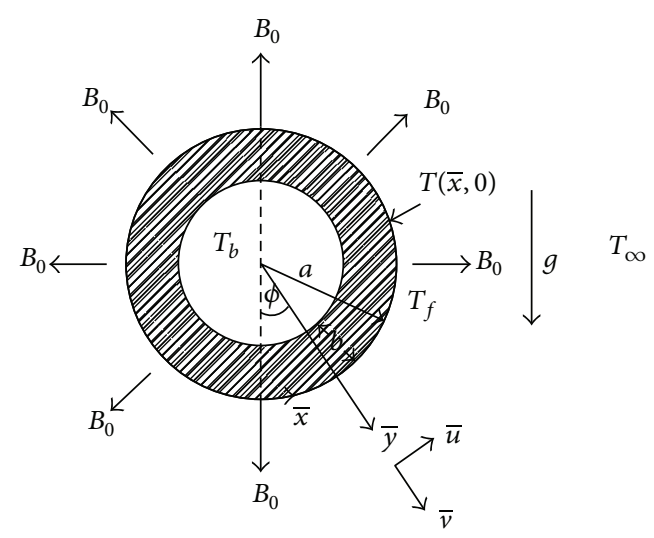

Figure 1: Physical model and coordinate system.

regime, the following nondimensional variables are introduced with Grashof number $\mathrm{Gr}=\left[g \beta a^{3}\left(T_{b}-T_{\infty}\right)\right] / \nu^{2}$ :

$$
\begin{gathered}
x=\frac{\bar{x}}{a}, \quad y=\frac{\bar{y}}{a} \mathrm{Gr}^{1 / 4}, \quad u=\frac{\bar{u} a}{v} \mathrm{Gr}^{-1 / 2}, \\
v=\frac{\bar{v} a}{v} \mathrm{Gr}^{-1 / 4}, \quad \theta=\frac{T_{f}-T_{\infty}}{T_{b}-T_{\infty}},
\end{gathered}
$$

where $\theta$ is the dimensionless temperature. The nondimensional forms of the governing equations (1)-(3) are as follows:

$$
\begin{gathered}
\frac{\partial u}{\partial x}+\frac{\partial v}{\partial y}=0 \\
u \frac{\partial u}{\partial x}+v \frac{\partial v}{\partial y}+M u=\frac{\partial^{2} u}{\partial y^{2}}+\theta \sin x \\
u \frac{\partial \theta}{\partial x}+v \frac{\partial \theta}{\partial y}=\frac{1}{\operatorname{Pr}} \frac{\partial^{2} \theta}{\partial y^{2}}+J u^{2}+Q \theta
\end{gathered}
$$

where $M=\sigma a^{2} B_{0}{ }^{2} / \nu \rho \mathrm{Gr}^{1 / 2}$ is the magnetic parameter, $J=$ $\sigma \nu B_{0}{ }^{2} \mathrm{Gr}^{1 / 2} / \rho c_{p}\left(T_{b}-T_{\infty}\right)$ is the Joule heating parameter, $Q=$ $Q_{0} a^{2} / \mu c_{p} \mathrm{Gr}^{1 / 2}$ is the heat generation parameter, and $\operatorname{Pr}=$ $\mu c_{p} / \kappa$ is the Prandtl number.

The boundary condition (4) can be written as in the following dimensionless form:

$$
\begin{gathered}
u=v=0, \quad \theta-1=\chi \frac{\partial \theta}{\partial y}, \quad \text { on } y=0, x>0, \\
u \longrightarrow 0, \quad \theta \longrightarrow 0 \text { as } y \longrightarrow \infty, x>0,
\end{gathered}
$$

where $\chi=\left(b \kappa_{f} / a \kappa_{s}\right) \mathrm{Gr}^{1 / 4}$ is the conjugate conduction parameter. The present problem is governed by the magnitude of magnetic parameter $M$, Joule heating parameter $J$, heat generation parameter $Q$, and conjugate conduction parameter $\chi$. The values of $\chi$ depend upon the ratios of $b / a$ and $\kappa_{f} / \kappa_{s}$ and Grashof number Gr. The ratios $b / a$ and $\kappa_{f} / \kappa_{s}$ are less than unity whereas $\mathrm{Gr}$ is large for free convection. Therefore, the value of $\chi$ is greater than zero. Present analysis will refer to the free convection problem without conduction for $\chi=0$.
To solve (6)-(8), subject to the boundary condition (9), we assume the following transformations:

$$
\psi=x f(x, y), \quad \theta=\theta(x, y),
$$

where $\theta$ is the dimensionless temperature and $\psi$ is the stream function usually defined as follows:

$$
u=\frac{\partial \psi}{\partial y}, \quad v=-\frac{\partial \psi}{\partial x} .
$$

Substituting (11) into (6)-(9), new forms of the dimensionless equations (7) and (8) are

$$
\begin{gathered}
\frac{\partial^{3} f}{\partial y^{3}}+f \frac{\partial^{2} f}{\partial y^{2}}-\left(\frac{\partial f}{\partial y}\right)^{2}-M \frac{\partial f}{\partial y}+\theta \frac{\sin x}{x} \\
=x\left(\frac{\partial f}{\partial y} \frac{\partial^{2} f}{\partial x \partial y}-\frac{\partial^{2} f}{\partial y^{2}} \frac{\partial f}{\partial x}\right) \\
\frac{1}{\operatorname{Pr}} \frac{\partial^{2} \theta}{\partial y^{2}}+f \frac{\partial \theta}{\partial y}+J x^{2}\left(\frac{\partial f}{\partial y}\right)^{2}+Q \theta=x\left(\frac{\partial f}{\partial y} \frac{\partial \theta}{\partial x}-\frac{\partial \theta}{\partial y} \frac{\partial f}{\partial x}\right)
\end{gathered}
$$

The corresponding boundary conditions as mentioned in (9) take the following form:

$$
\begin{gathered}
f=\frac{\partial f}{\partial y}=0, \quad \theta-1=\chi \frac{\partial \theta}{\partial y} \quad \text { at } y=0, x>0, \\
\frac{\partial f}{\partial y} \longrightarrow 0, \quad \theta \longrightarrow 0 \quad \text { as } y \longrightarrow \infty, x>0 .
\end{gathered}
$$

Equations (12) and (13) are solved numerically using implicit finite difference method using Keller box scheme [18, 19] based on the boundary conditions described in (14). The shearing stress and the rate of heat transfer in terms of skin friction coefficient and Nusselt number, respectively, can be written as [15]

$$
C_{f}=\frac{\tau_{w}}{\rho U_{\infty}^{2}}, \quad \mathrm{Nu}=\frac{a q_{w}}{\kappa\left(T_{w}-T_{\infty}\right)},
$$

where $\tau_{w}=\mu(\partial \bar{u} / \partial \bar{y})_{\bar{y}=0}$ and $q_{w}=-\kappa(\partial T / \partial \bar{y})_{\bar{y}=0 \text {. }}$

Using the variables (5) and the boundary conditions into (14), we have

$$
C_{f} \mathrm{Gr}^{1 / 4}=x f^{\prime \prime}(x, 0), \quad \mathrm{Nu} \mathrm{Gr}^{-1 / 4}=-\theta^{\prime}(x, 0) .
$$

The results of the velocity profiles and temperature distributions can be calculated by the following relations:

$$
u=f^{\prime}(x, y), \quad \theta=\theta(x, y) .
$$

In (16) and (17) primes denote differentiation with respect to $y$ only.

\section{Method of Solution}

In the present studies, we have employed implicit finite difference method, which was introduced by Keller [18] 
TABLE 1: Comparisons of the present numerical values with Merkin [1] and Molla et al. [15] for different values of $x$ while with Pr $=1.0$, $M=0.0, \chi=0.0, J=0.0$, and $Q=0.0$.

\begin{tabular}{|c|c|c|c|c|c|c|}
\hline \multirow{2}{*}{$x$} & \multicolumn{3}{|c|}{$\mathrm{Nu} \mathrm{Gr}^{-1 / 4}=-\theta^{\prime}(x, 0)$} & \multicolumn{3}{|c|}{$C_{f} \mathrm{Gr}^{1 / 4}=x f^{\prime \prime}(x, 0)$} \\
\hline & Merkin [1] & Molla et al. [15] & Present & Merkin [1] & Molla et al. [15] & Present \\
\hline 0.0 & 0.4214 & 0.4214 & 0.4216 & 0.0000 & 0.0000 & 0.0000 \\
\hline$\pi / 6$ & 0.4161 & 0.4161 & 0.4163 & 0.4151 & 0.4145 & 0.4139 \\
\hline$\pi / 3$ & 0.4007 & 0.4005 & 0.4006 & 0.7558 & 0.7539 & 0.7528 \\
\hline$\pi / 2$ & 0.3745 & 0.3740 & 0.3742 & 0.9579 & 0.9541 & 0.9526 \\
\hline $2 \pi / 3$ & 0.3364 & 0.3355 & 0.3356 & 0.9756 & 0.9696 & 0.9678 \\
\hline $5 \pi / 6$ & 0.2825 & 0.2812 & 0.2811 & 0.7822 & 0.7739 & 0.7718 \\
\hline$\pi$ & 0.1945 & 0.1917 & 0.1912 & 0.3391 & 0.3264 & 0.3239 \\
\hline
\end{tabular}

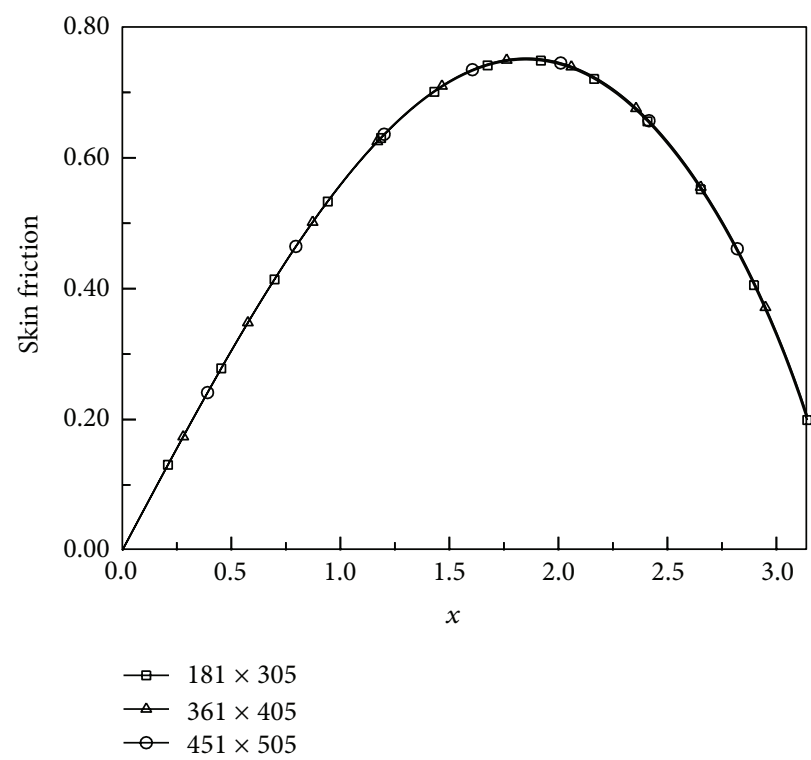

(a)

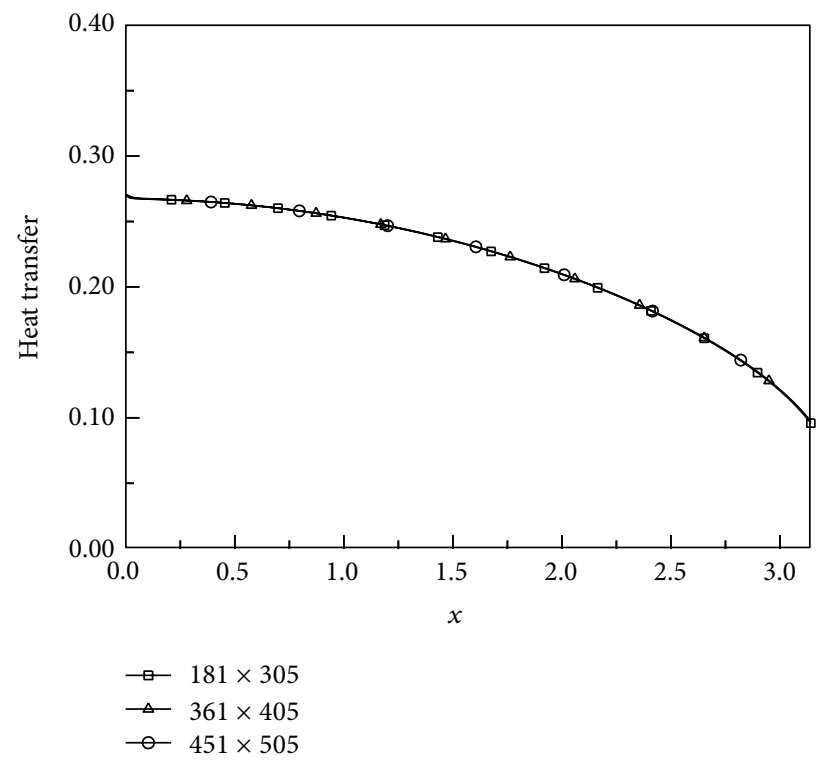

(b)

Figure 2: (a) The skin friction coefficient and (b) the rate of heat transfer against $x$ for different mesh configurations while $\operatorname{Pr}=1.0, M=0.1$, $\chi=1.0, J=0.01$, and $Q=0.01$.

and elaborately described by Cebeci and Bradshaw [19]. A brief discussion of the development of an algorithm of implicit finite difference method together with the Keller box elimination scheme of the present analysis is given below.

Equations (12) and (13) are written in terms of first-order equations in $y$, which are then expressed in finite difference form by approximating the functions and their derivatives in terms of the central differences in both coordinate directions. Denoting the mesh points in the $(x, y)$ plane by $x_{i}$ and $y_{j}$, where $i=1,2,3, \ldots, 181$ and $j=1,2,3, \ldots, 305$, central difference approximations are made such that the equations involving $x$ explicitly are centered at $\left(x_{i-1 / 2}, y_{j-1 / 2}\right)$ and the remainder at $\left(x_{i}, y_{j-1 / 2}\right)$, where $y_{j-1 / 2}=\left(y_{j}+y_{j-1}\right) / 2$ and so forth. This results in a set of nonlinear difference equations for the unknowns at $x_{i}$ in terms of their values at $x_{i-1}$. These equations are then linearised by the Newton's method and are solved using a block-tridiagonal algorithm, taken as the initial iteration of the converged solution at $x=x_{i-1}$. Now to initiate the process at $x=0$, we first provide guess profiles for all five variables (arising the reduction to the first-order form) and use the Keller box method to solve the governing ordinary differential equations. Having obtained the lower stagnation point solution, it is possible to march step by step along the boundary layer. For a given value of $x$, the iterative procedure is stopped when the difference in computing the velocity and the temperature in the next iteration is less than $10^{-6}$, that is, when $\left|\delta f^{i}\right| \leq 10^{-6}$, where the superscript denotes the iteration number. The computations were not performed using a uniform grid in the $y$ direction, but a nonuniform grid was used and defined by $y_{j}=\sinh ((j-1) / p)$, with $j=1,2, \ldots, 305$ and $p=100$.

\section{Results and Discussion}

The dimensionless governing equations (12) and (13) and the boundary conditions (14) contain a set of physical parameters: Prandtl number $\operatorname{Pr}$, magnetic parameter $M$, conjugate conduction parameter $\chi$, Joule heating parameter $J$, and heat generation parameter $Q$. The Prandtl numbers are considered to be $1.63,1.44,1.0$, and 0.733 that correspond to Glycerin, 


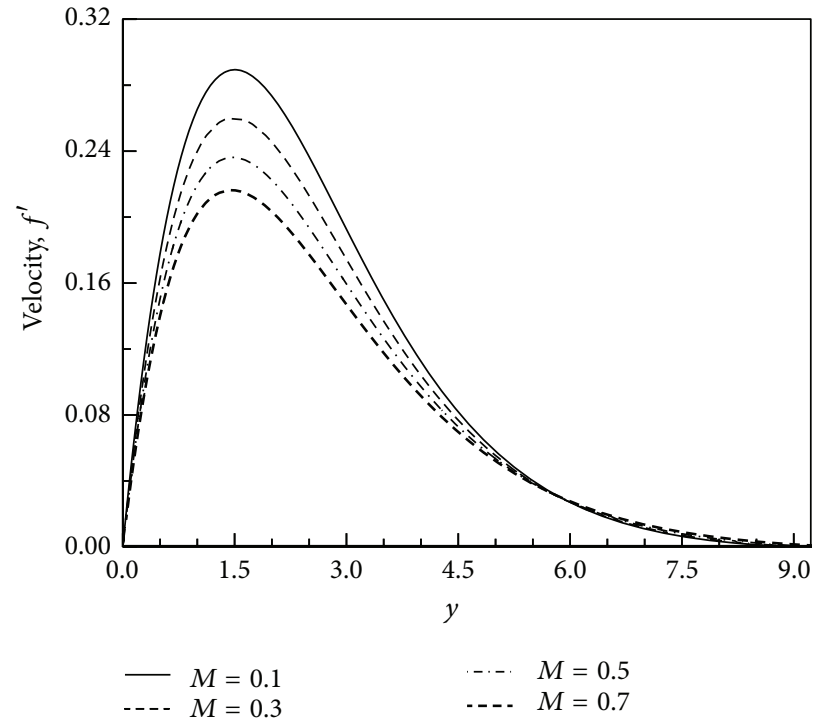

(a)

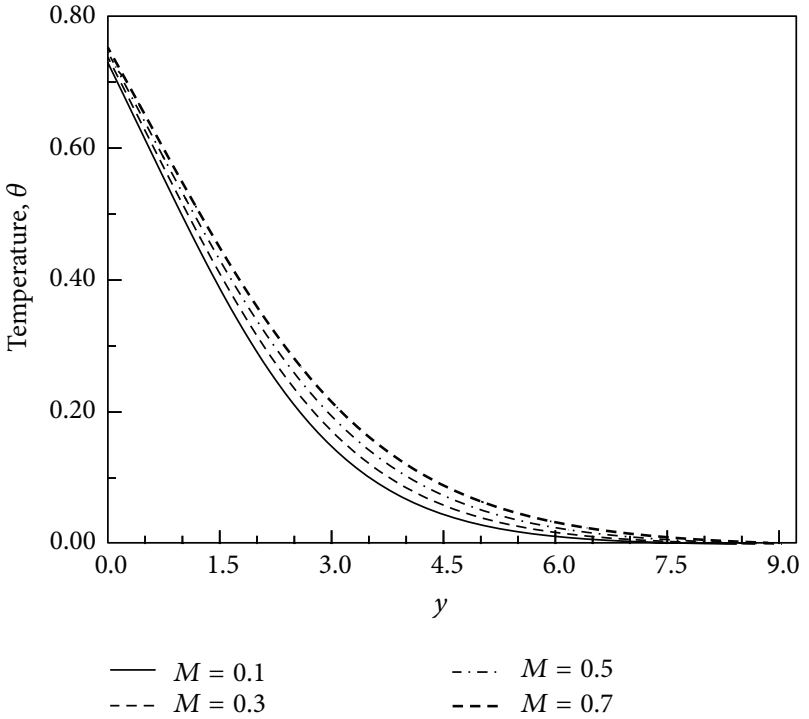

(b)

FIGURE 3: (a) Variation of velocity profiles and (b) variation of temperature distributions against $y$ for varying of magnetic parameter $M$ with $\operatorname{Pr}=1.0, \chi=1.0, J=0.01$, and $Q=0.01$.

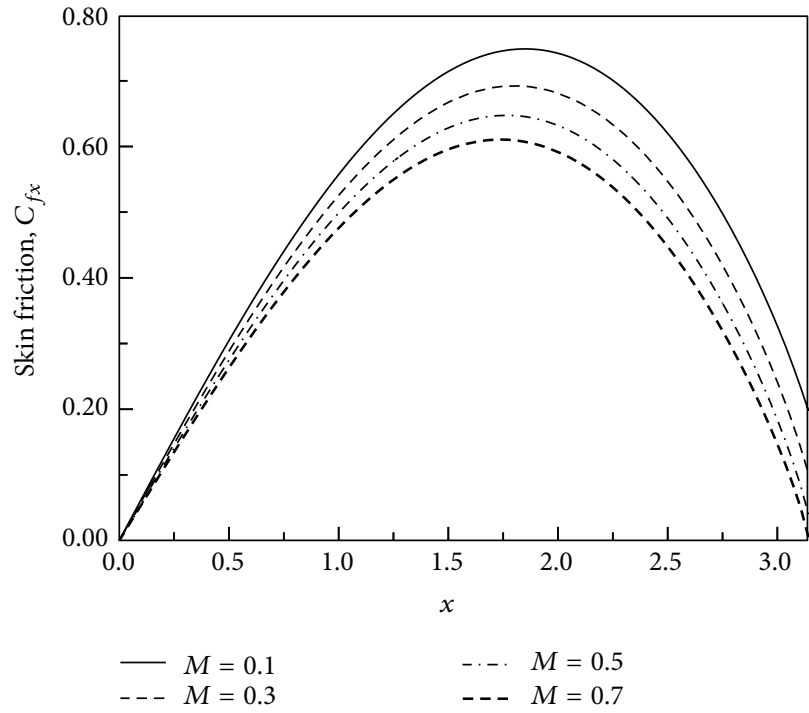

(a)

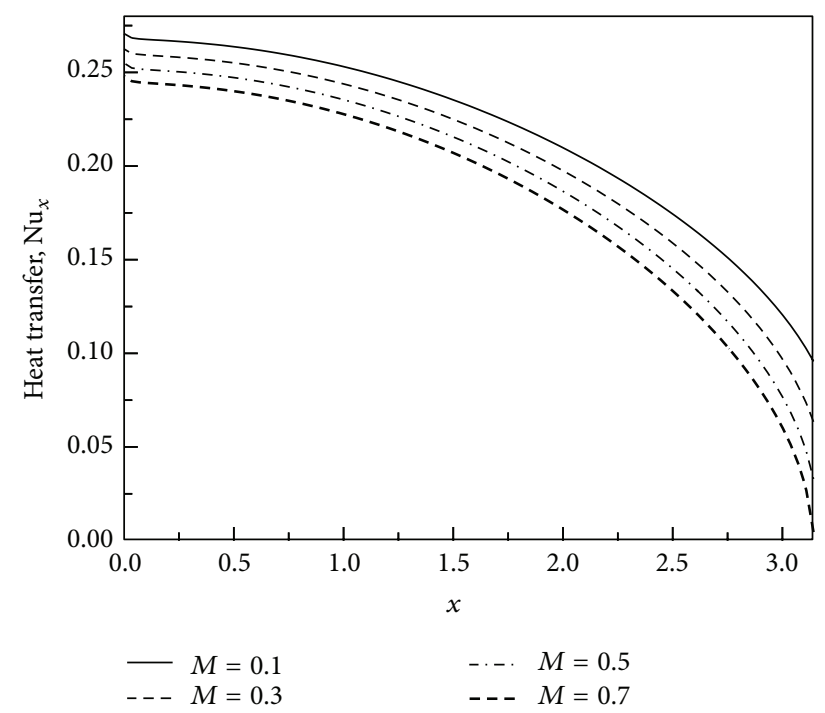

(b)

FIGURE 4: (a) Variation of skin friction coefficients and (b) variation of rate of heat transfer against $x$ for varying of $M$ with $\operatorname{Pr}=1.0, \chi=1.0$, $J=0.01$, and $Q=0.01$.

water, steam, and hydrogen, respectively. The remaining parameters are taken as follows: magnetic parameter $M=$ 0.10-0.70; conjugate conduction parameter $\chi=1.0-2.5$; Joule heating parameter $J=0.01-1.0$; and heat generation parameter $Q=0.01-0.12$.

A comparison of the local Nusselt number and the local skin friction factor obtained in the present work with $M=$ $0.0, \chi=0.0, J=0.0, Q=0.0$, and $\operatorname{Pr}=1.0$ and obtained by Merkin [1] and Molla et al. [15] has been shown in Table 1, and it has been observed that there is an excellent agreement among these three results.
A grid independent test has been shown by taking three different grid configurations, $181 \times 305,361 \times 405$, and $451 \times 505$, in Figures $2(\mathrm{a})$ and $2(\mathrm{~b})$ as the skin friction coefficient and the rate of heat transfer while $\operatorname{Pr}=1.0$, $M=0.1, \chi=1.0, J=0.01$, and $Q=0.01$. From these figures, it can be concluded that the numerical solutions are completely independent of the grid orientations. In the present investigation $181 \times 305$ grid configuration has been chosen for the numerical computation.

Figures 3, 5, 7, 9, and 11 illustrate the velocity and temperature distributions at $x=\pi / 2$ against $y$, the direction 


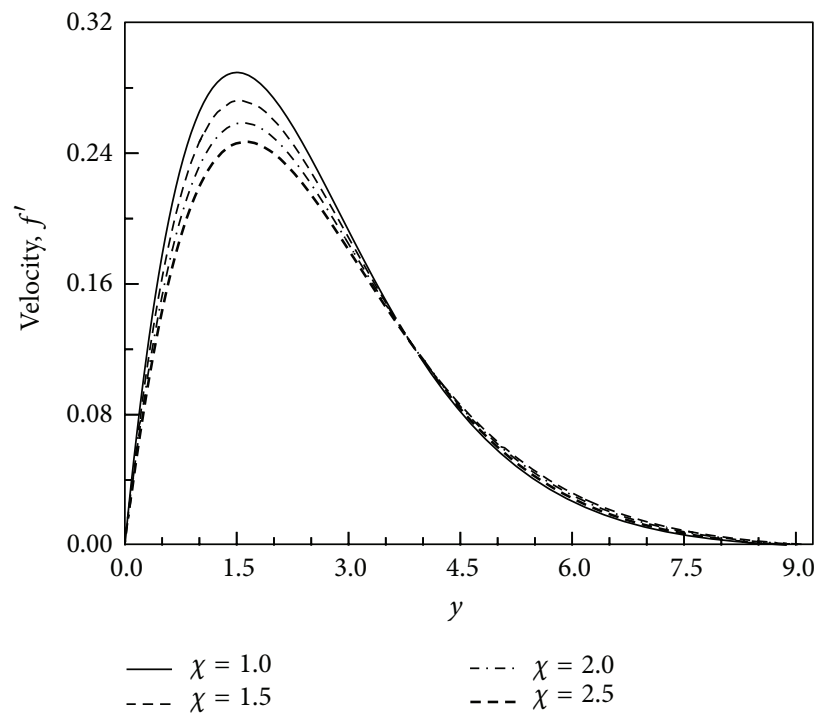

(a)

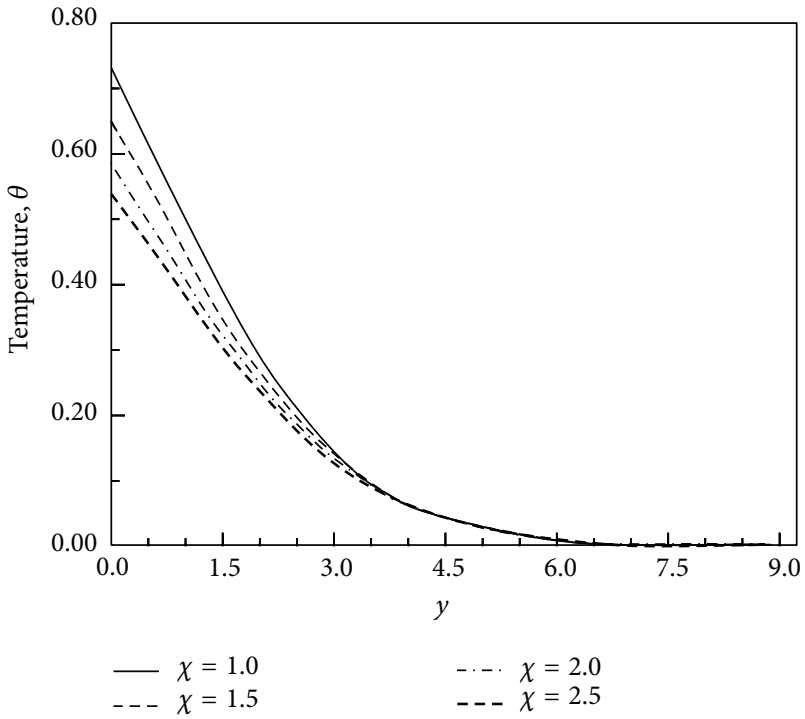

(b)

FIGURE 5: (a) Variation of velocity profiles and (b) variation of temperature distributions against $y$ for varying of conjugate conduction parameter $\chi$ with $\operatorname{Pr}=1.0, M=0.1, J=0.01$, and $Q=0.01$.

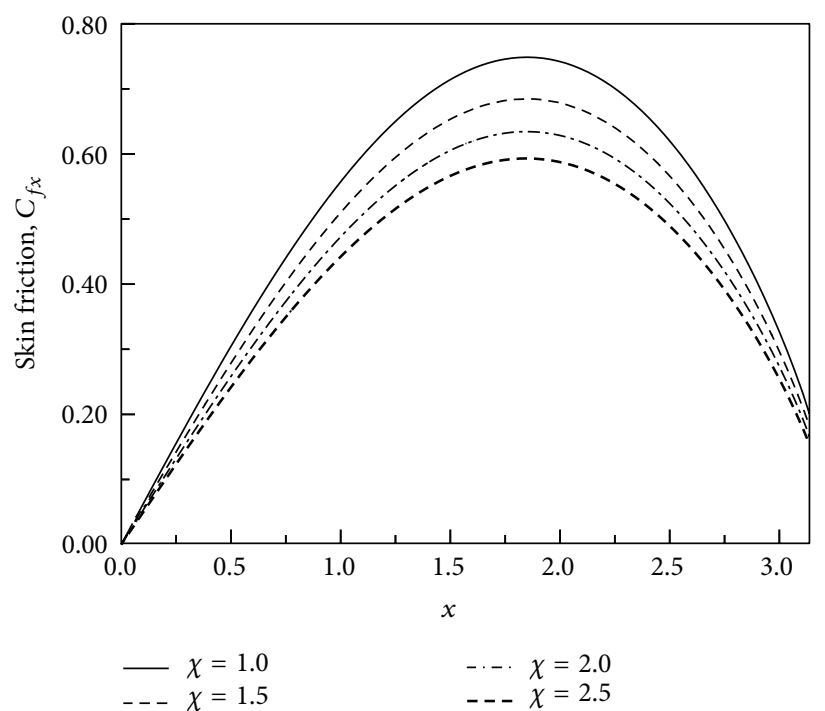

(a)

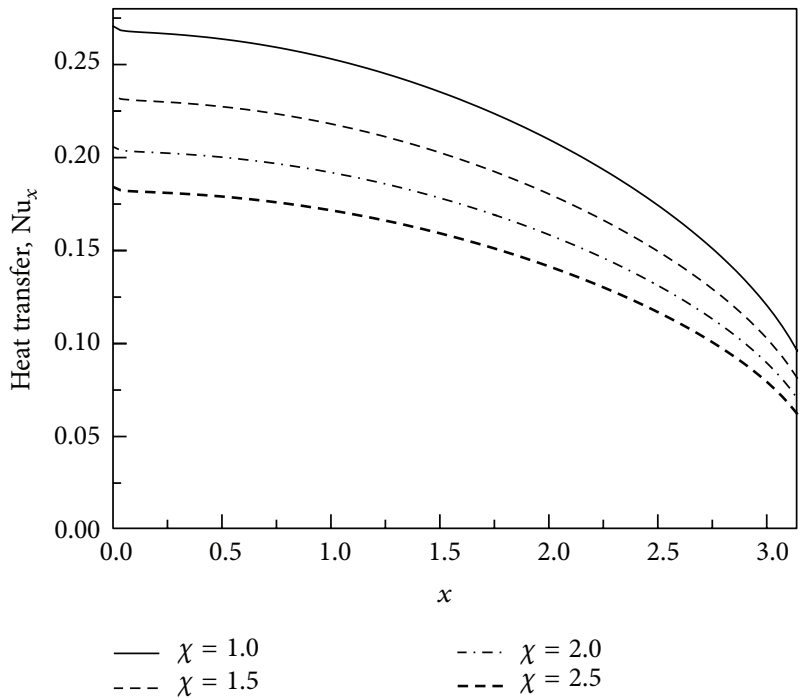

(b)

FIGURE 6: (a) Variation of skin friction coefficients and (b) variation of rate of heat transfer against $x$ for varying of conjugate conduction parameter $\chi$ with $\operatorname{Pr}=1.0, M=0.1, J=0.01$, and $Q=0.01$.

along the normal to the surface of the cylinder, and Figures 4, $6,8,10$, and 12 depict the skin friction coefficients and heat transfer rates against $x$ at $y=0$ (along the surface of the cylinder) for different values of the magnetic parameter, conjugate conduction parameter, Prandtl number, Joule heating parameter, and heat generation parameter, respectively.

The magnetic parameter is the ratio of the magnetic force to the inertia force. Hence the magnetic force is important when it is the order of one, and the flow is considered as hydromagnetic flow. The flow is hydrodynamic for $M \ll$ 1. For small value of $M$, the motion is hardly affected by the magnetic field and for large value of $M$, the motion is largely controlled by the magnetic field. The increasing values of the magnetic parameters increase magnetic-field strength, which is acting normal to the cylinder surface that reduces fluid motion as observed in Figure 3(a). As a result the skin friction at the surface to the cylinder is decreased, which is shown from Figure 4(a). Heat is produced due to the interaction between magnetic field and fluid motion; consequently, temperature within the thermal boundary layer increases for increasing value of the magnetic parameters as revealed from Figure 3(b). Increasing thermal energy within the boundary 


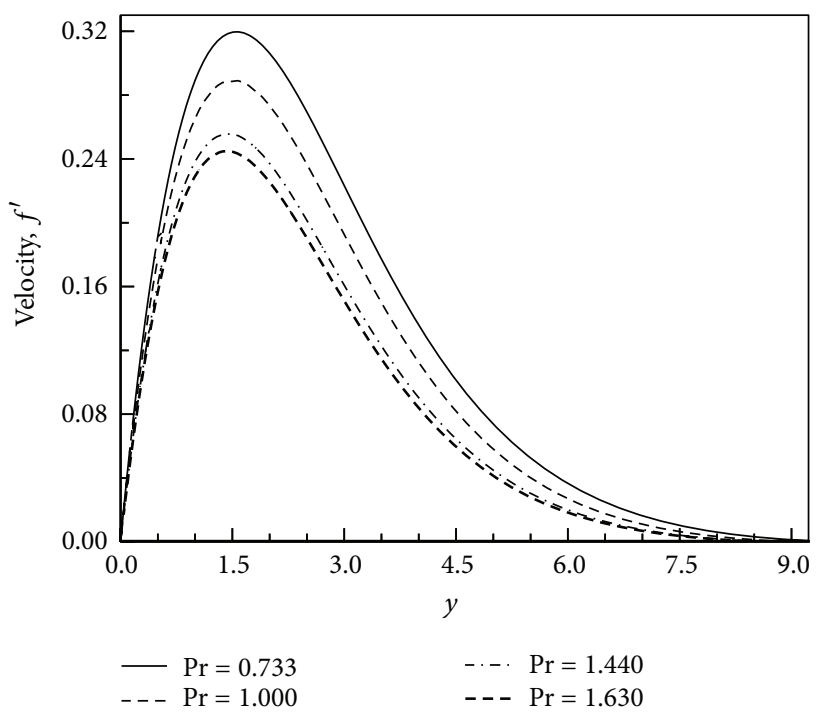

(a)

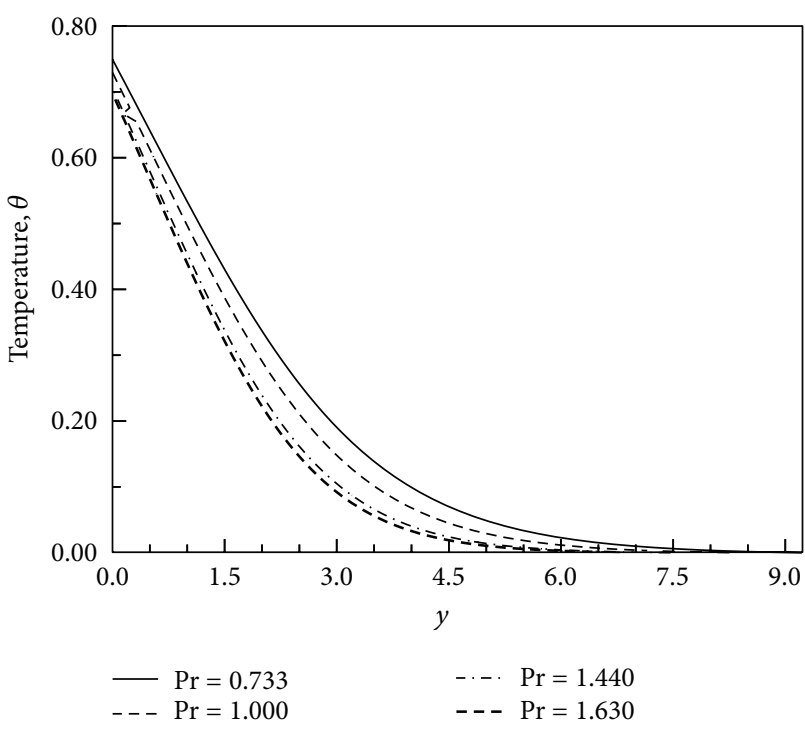

(b)

FiguRE 7: (a) Variation of velocity profiles and (b) variation of temperature distributions against $y$ for varying of $\operatorname{Pr}$ with $M=0.1, \chi=1.0$, $J=0.01$, and $Q=0.01$.

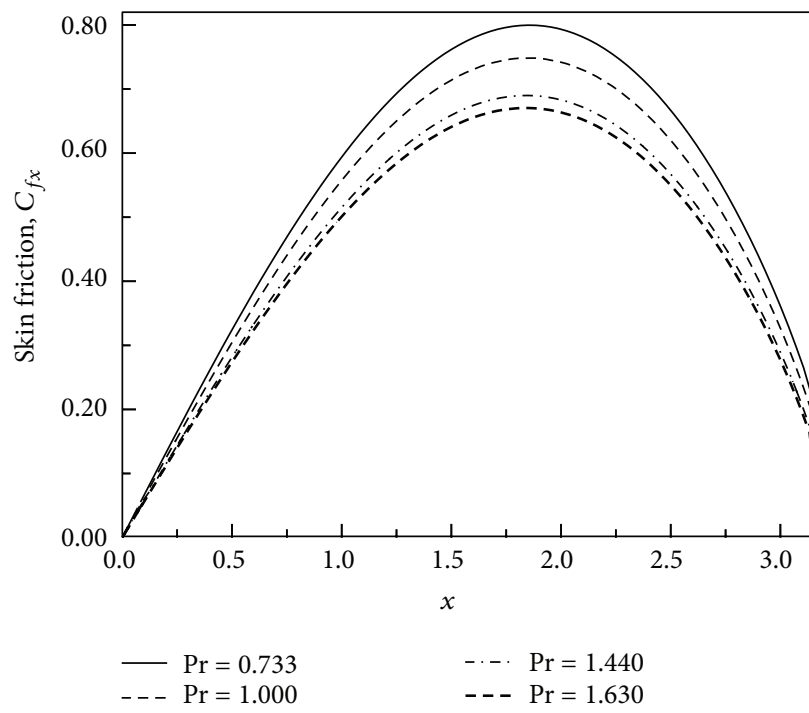

(a)

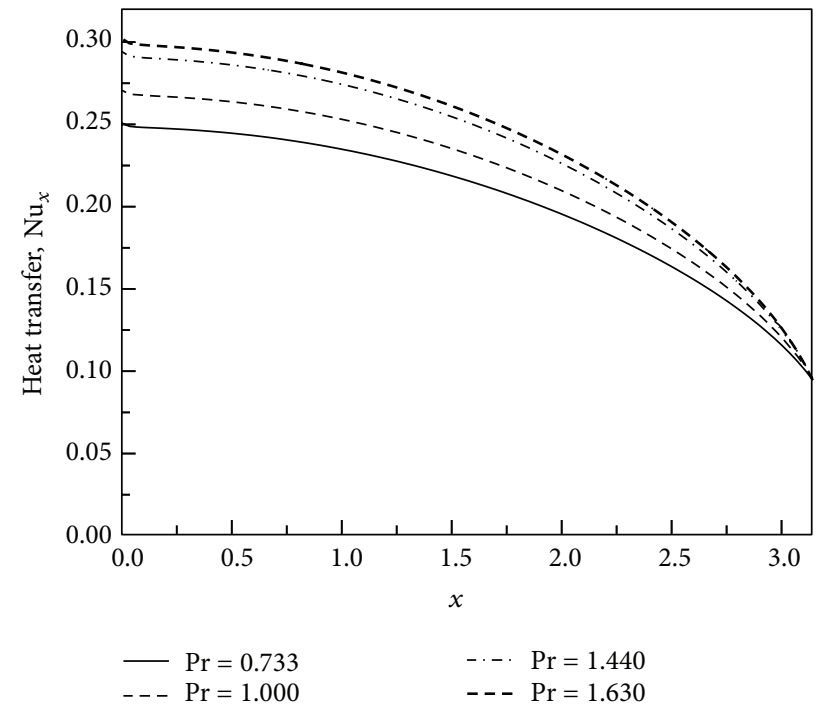

(b)

FIGURE 8: (a) Variation of skin friction coefficients and (b) variation of rate of heat transfer against $x$ for varying of $\operatorname{Pr}$ with $M=0.1, \chi=1.0$, $J=0.01$, and $Q=0.01$.

layer reduces the temperature difference between core region and boundary layer region, which ultimately decreases the heat transfer rate as illustrated in Figure 4(b).

The velocity and temperature are illustrated in Figure 5 and the variation of the local skin friction coefficient and local rate of heat transfer are depicted in Figure 6 for different values of conjugate conduction parameter $\chi$ with $\operatorname{Pr}=1.0$, $M=0.1, J=0.01$, and $Q=0.01$. Increasing value of conjugate conduction parameter $\chi$ resists conduction from the core region to the boundary layer and consequently, decelerates convection within the boundary layer, as a result velocity and temperature decrease for increasing values of the conjugate conduction parameters at a particular value of $y$, which are presented in Figures 5(a) and 5(b), respectively. As the velocity decreases, the skin friction at the surface decreases for increasing value of conjugate conduction parameter $\chi$, as observed in Figure 6(a). Since increasing value of the conjugate conduction parameters resists conduction from 


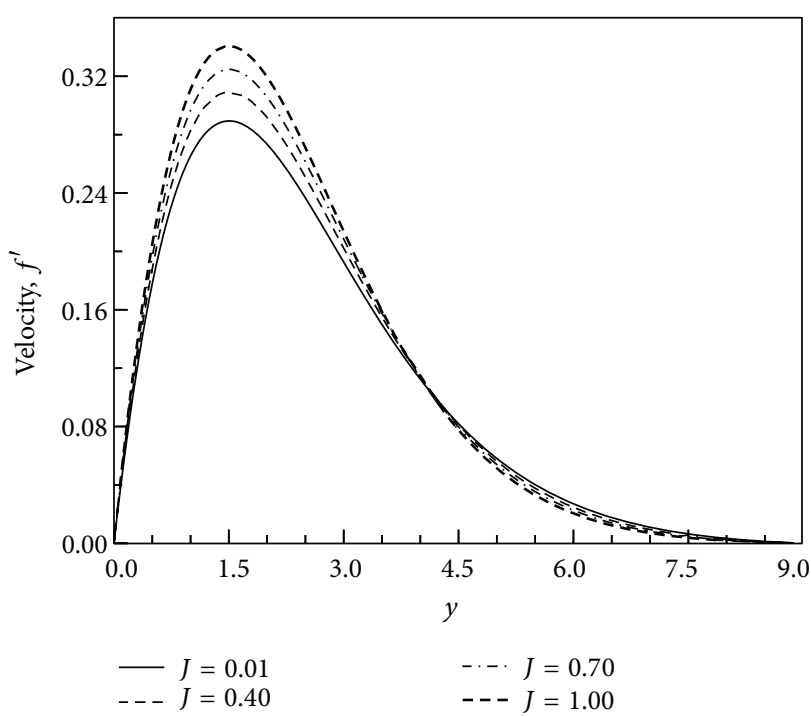

(a)

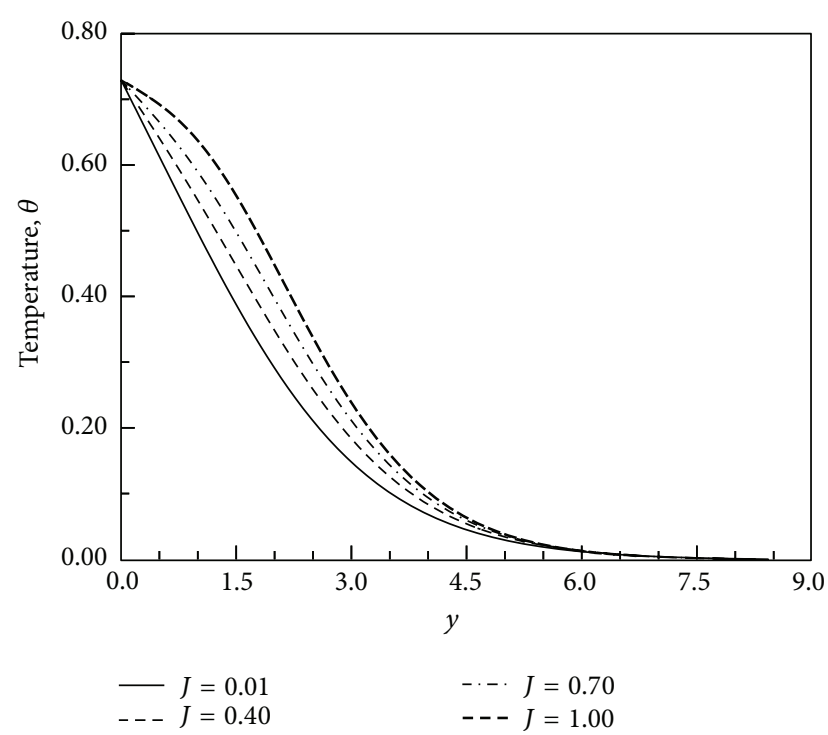

(b)

Figure 9: (a) Variation of velocity profiles and (b) variation of temperature distributions against $y$ for varying of $J$ with $\operatorname{Pr}=1.0, M=0.1$, $\chi=1.0$, and $Q=0.01$.

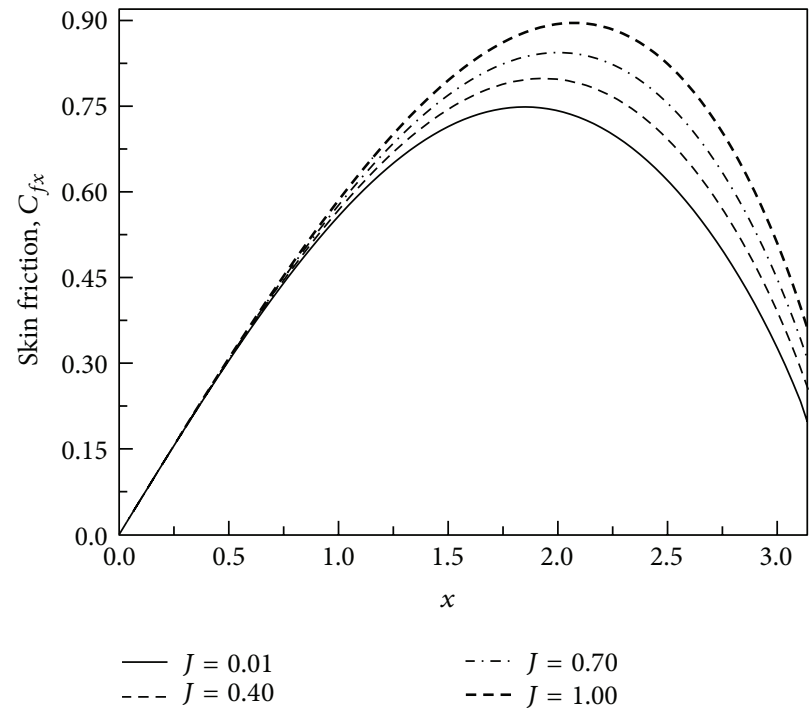

(a)

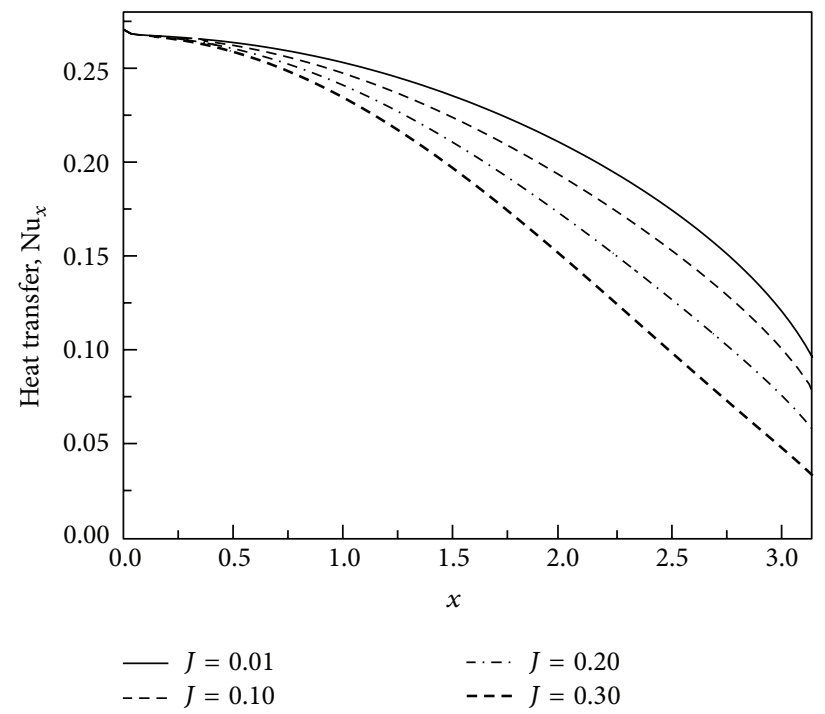

(b)

FIGURE 10: (a) Variation of skin friction coefficients and (b) variation of rate of heat transfer against $x$ for varying of $J$ with $\operatorname{Pr}=1.0, M=0.1$, $\chi=1.0$, and $Q=0.01$.

the core region to the boundary layer as mentioned earlier, it of course resists thermal energy transfer which is observed from Figure 6(b).

The increasing value of Prandtl number increases viscosity and decreases the thermal action of the fluid. Therefore, the velocity and temperature of fluid are expected to decrease with the increasing Prandtl number which are observed in Figures 7(a) and 7(b), respectively. Decreasing velocity of the fluid leads to decrease skin friction and the decreasing temperature within in the boundary layer increases the temperature difference between core (inner) region and boundary layer region, which eventually increases heat transfer rate from the core region to the boundary layer region as depicted in Figures 8(a) and 8(b), respectively.

The effects of the Joule heating parameters on the velocity and temperature are presented in Figure 9, and on the skin friction and rate of heat transfer they are illustrated in Figure 10, respectively, with $\operatorname{Pr}=1.0, M=0.1, \chi=$ 1.0 , and $Q=0.01$. The Joule heating parameter having the magnetic-field strength increases the temperature and 


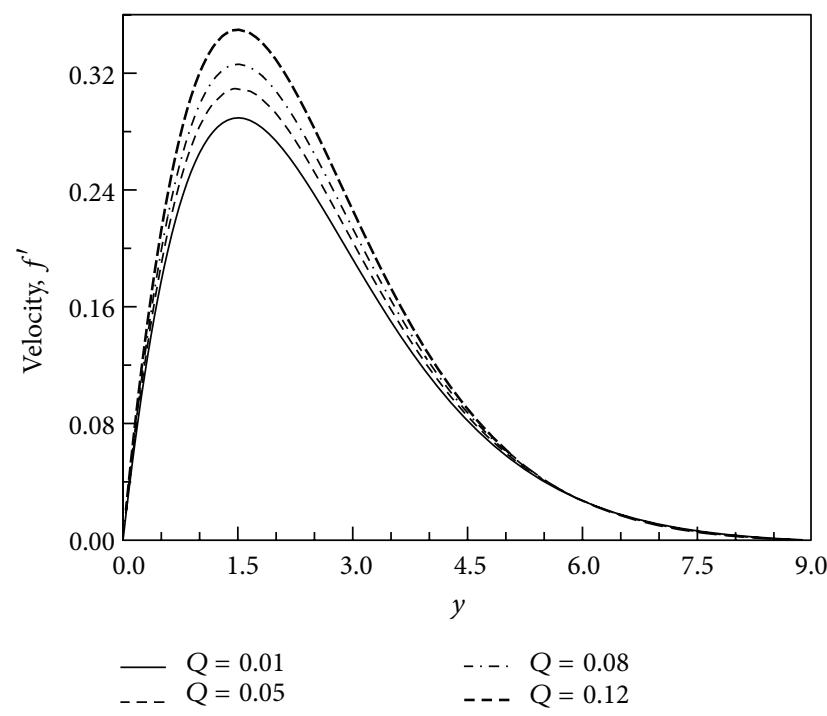

(a)

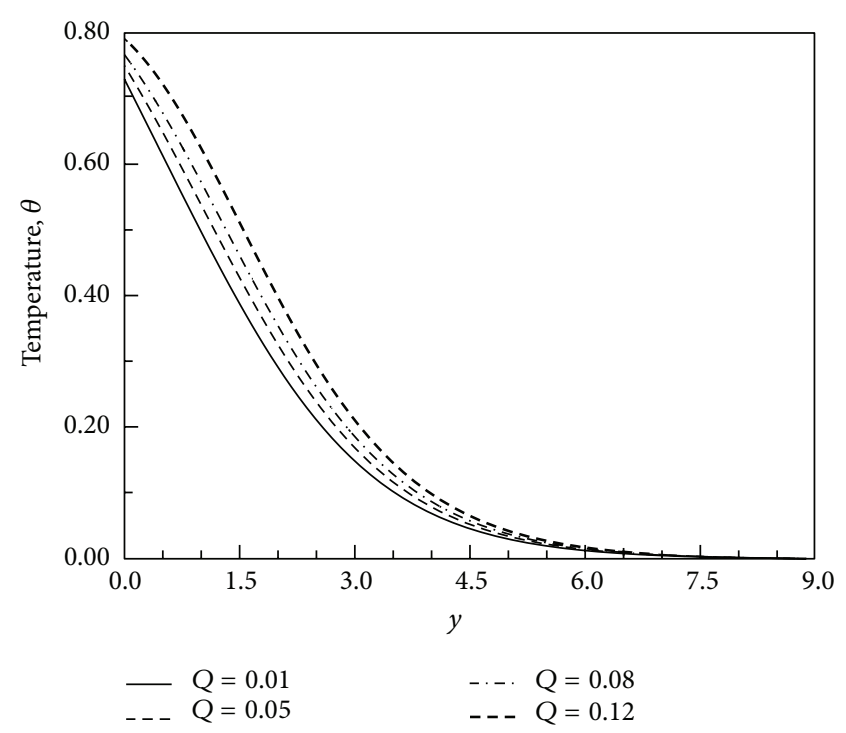

(b)

FIGURE 11: (a) Variation of velocity profiles and (b) variation of temperature distributions against $y$ for varying of $Q$ with $\operatorname{Pr}=1.0, M=0.1$, $\chi=1.0$, and $J=0.01$.

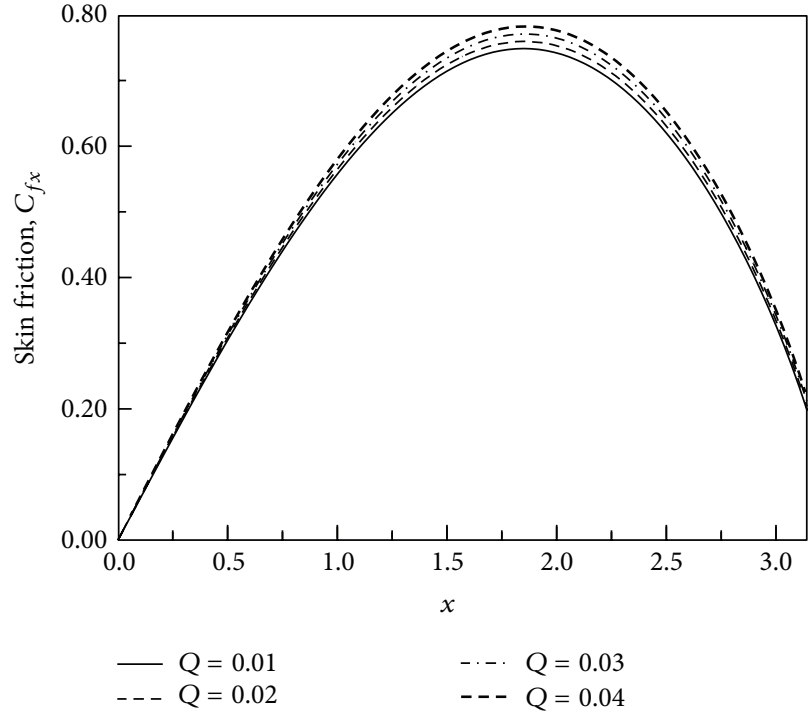

(a)

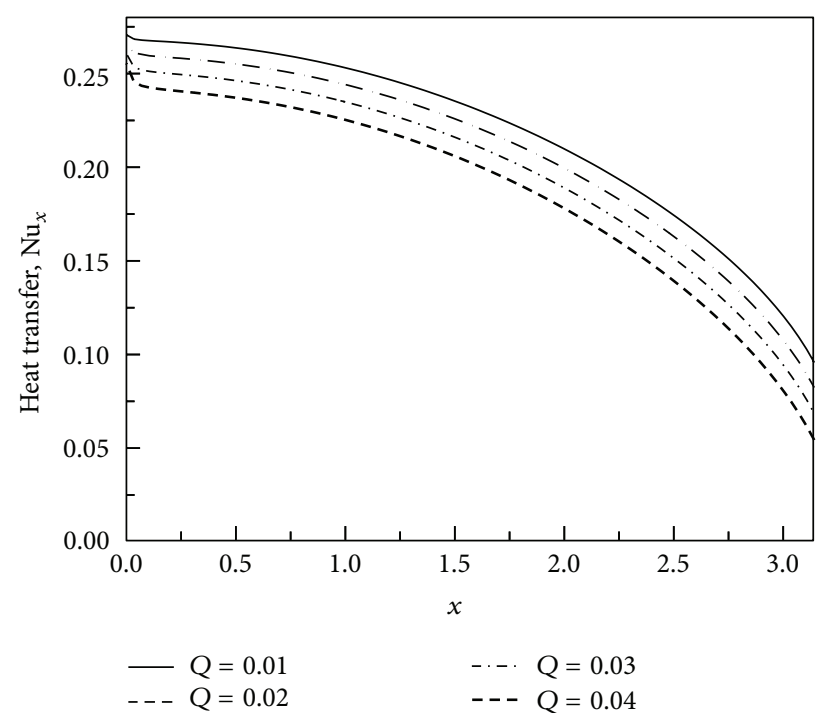

(b)

FIGURE 12: (a) Variation of skin friction coefficients and (b) variation of rate of heat transfer against $x$ for varying of $Q$ with $\operatorname{Pr}=1.0, M=0.1$, $\chi=1.0$, and $J=0.01$.

eventually the fluid motion is accelerated as plotted in Figures 9(b) and 9(a), respectively. The increased temperature for increasing Joule heating parameter increases the temperature within the boundary layer which results in the heat transfer rate decrease as illustrated in Figure 10(b). The variation of local skin friction coefficient increases for the increasing $J$ as depicted in Figure 10(a). This is an expected behavior as fluid motion increases for increasing Joule heating parameter.

Figure 11 illustrates the effect of the heat generation parameters on the fluid velocity and temperature profiles, respectively. It is clear that as the heat generation parameter increases both the fluid velocity and temperature of the fluid increase. Figure 12 depicts the variation of the heat generation parameters on the skin friction coefficient and the heat transfer rate with $\operatorname{Pr}=1.0, M=0.1, \chi=1.0$, and $J=0.01$. It is observed that the local Nusselt number decreases, but the skin friction coefficient increases with increasing heat generation parameter.

\section{Conclusion}

MHD-conjugate natural convection flow from horizontal cylinder taking into account Joule heating in the presence of 
heat generation is studied. Numerical results were obtained for the physical parameters and discussed. From the results, it is established that the velocity of the fluid within the boundary layer decreases with increasing magnetic parameter, conjugate conduction parameter, and Prandtl number while it increases for increasing Joule heating parameter, and heat generation parameter. The temperature within the boundary layer increases for increasing magnetic parameter, Joule heating parameter and heat generation parameter whereas it decreases for increasing conjugate conduction parameter and Prandtl number. Moreover, the skin friction along the surface of the cylinder decreases for increasing magnetic parameter, conjugate conduction parameter, and Prandtl number, and it increases for increasing Joule heating parameter and heat generation parameter. Furthermore, the rate of heat transfer along the surface increases for increasing Prandtl number while it decreases for remaining parameters.

\section{Nomenclature}

$a$ : Outer radius of the cylinder

$b$ : Thickness of the cylinder

$B_{0}$ : Applied magnetic field

$C_{f x}$ : Skin friction coefficient

$c_{p}:$ Specific heat

$f:$ Dimensionless stream function

$g$ : Acceleration due to gravity

$J$ : Joule heating parameter

M: Magnetic parameter

$\mathrm{Nu}_{x}$ : Local Nusselt number

Pr: Prandtl number

Q: Heat generation parameter

$T_{f}$ : Temperature at the boundary layer region

$T_{s}$ : Temperature of the solid of the cylinder

$T_{b}$ : Temperature of the inner cylinder

$T_{\infty}$ : Temperature of the ambient fluid

$\bar{u}, \bar{v}$ : Velocity components

$u, v$ : Dimensionless velocity components

$U_{\infty}$ : Dimensionless free stream velocity

$\bar{x}, \bar{y}$ : Cartesian coordinates

$\beta$ : Coefficient of thermal expansion

$\chi$ : Conjugate conduction parameter

$\psi:$ Dimensionless stream function

$\rho$ : Density of the fluid

$\nu$ : Kinematic viscosity

$\mu$ : Viscosity of the fluid

$\theta$ : Dimensionless temperature

$\sigma: \quad$ Electrical conductivity

$\kappa_{f}$ : Thermal conductivity of the ambient fluid

$\kappa_{s}$ : Thermal conductivity of the ambient solid.

\section{References}

[1] J. H. Merkin, "Free convection boundary-layer on an isothermal horizontal cylinder," in Proceedings of the ASME-AIChE Heat Transfer Conference, pp. 1-4, St. Louis, Miss, USA, 1976.

[2] T. H. Kuehn and R. J. Goldstein, "Numerical solution to the Navier-Stokes equations for laminar natural convection about a horizontal isothermal circular cylinder," International Journal of Heat and Mass Transfer, vol. 23, no. 7, pp. 971-979, 1980.

[3] P. Wang, R. Kahawita, and T. H. Nguyen, "Numerical computation of the natural convection flow about a horizontal cylinder using splines," Numerical Heat Transfer A, vol. 17, no. 2, pp. 191215, 1990.

[4] L. B. Gdalevich and V. E. Fertman, "Conjugate problems of natural convection," Inzhenerno-Fizicheskii Zhurnal, vol. 33, pp. 539-547, 1977.

[5] M. Miyamoto, J. Sumikawa, T. Akiyoshi, and T. Nakamura, "Effects of axial heat conduction in a vertical flat plate on free convection heat transfer," International Journal of Heat and Mass Transfer, vol. 23, no. 11, pp. 1545-1553, 1980.

[6] A. Pozzi and M. Lupo, "The coupling of conduction with laminar natural convection along a flat plate," International Journal of Heat and Mass Transfer, vol. 31, no. 9, pp. 1807-1814, 1988.

[7] S. Kimura and I. Pop, "Conjugate natural convection from a horizontal circular cylinder," Numerical Heat Transfer A, vol. 25, no. 3, pp. 347-361, 1994.

[8] G. Wilks, "Magnetohydrodynamic free convection about a semi-infinite vertical plate in a strong cross field," Zeitschrift für Angewandte Mathematik und Physik, vol. 27, no. 5, pp. 621-631, 1976.

[9] M. A. Hossain, "Viscous and Joule heating effects on MHD-free convection flow with variable plate temperature," International Journal of Heat and Mass Transfer, vol. 35, no. 12, pp. 3485-3487, 1992.

[10] T. K. Aldoss, Y. D. Ali, and M. A. Al-Nimr, "MHD mixed convection from a horizontal circular cylinder," Numerical Heat Transfer A, vol. 30, no. 4, pp. 379-396, 1996.

[11] M. F. El-Amin, "Combined effect of viscous dissipation and Joule heating on MHD forced convection over a non-isothermal horizontal cylinder embedded in a fluid saturated porous medium," Journal of Magnetism and Magnetic Materials, vol. 263, no. 3, pp. 337-343, 2003.

[12] K. Vajravelu and A. Hadjinicolaou, "Heat transfer in a viscous fluid over a stretching sheet with viscous dissipation and internal heat generation," International Communications in Heat and Mass Transfer, vol. 20, no. 3, pp. 417-430, 1993.

[13] A. J. Chamkha and I. Camille, "Effects of heat generation/absorption and thermophoresis on hydromagnetic flow with heat and mass transfer over a flat surface," International Journal of Numerical Methods for Heat and Fluid Flow, vol. 10, no. 4, pp. 432-448, 2000.

[14] F. Méndez and C. Treviño, "The conjugate conduction-natural convection heat transfer along a thin vertical plate with nonuniform internal heat generation," International Journal of Heat and Mass Transfer, vol. 43, no. 15, pp. 2739-2748, 2000.

[15] M. M. Molla, M. A. Hossain, and M. C. Paul, "Natural convection flow from an isothermal horizontal circular cylinder in presence of heat generation," International Journal of Engineering Science, vol. 44, no. 13-14, pp. 949-958, 2006.

[16] A. A. Mamun, Z. R. Chowdhury, M. A. Azim, and M. M. Molla, "MHD-conjugate heat transfer analysis for a vertical flat plate in presence of viscous dissipation and heat generation," International Communications in Heat and Mass Transfer, vol. 35, no. 10, pp. 1275-1280, 2008.

[17] M. A. Azim, A. A. Mamun, and M. M. Rahman, "Viscous Joule heating MHD-conjugate heat transfer for a vertical flat plate in the presence of heat generation," International Communications in Heat and Mass Transfer, vol. 37, no. 6, pp. 666-674, 2010. 
[18] H. B. Keller, "Numerical methods in the boundary layer theory," Annual Review of Fluid Mechanics, vol. 10, pp. 417-433, 1978.

[19] T. Cebeci and P. Bradshaw, Physical and Computational Aspects of Convective Heat Transfer, Springer, New York, NY, USA, 1984.

[20] I. Pop and D. B. Ingham, Convective Heat Transfer, Pergamon, Oxford, UK, 1st edition, 2001. 

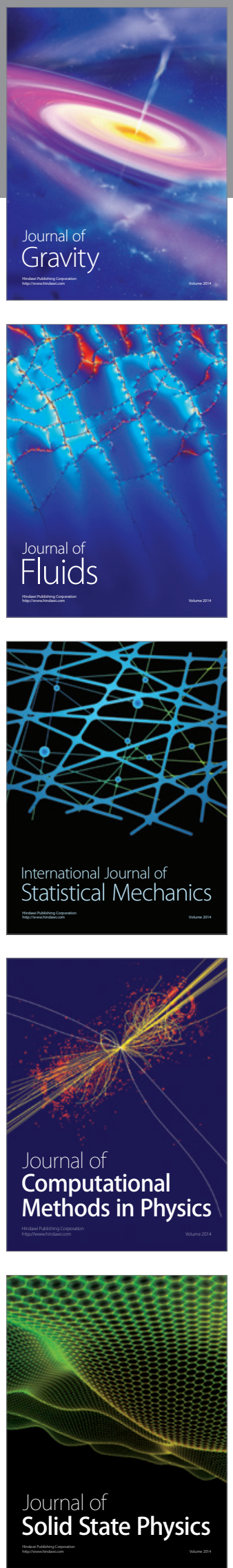

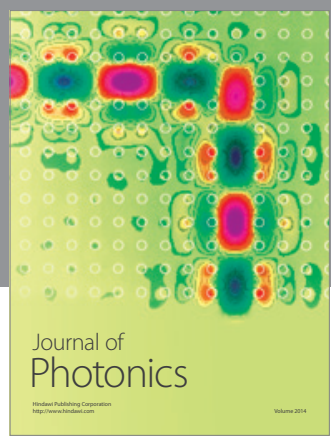

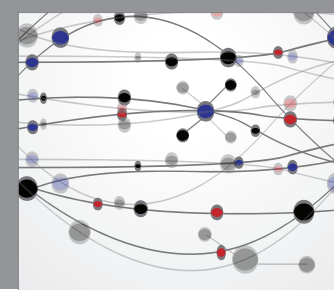

The Scientific World Journal

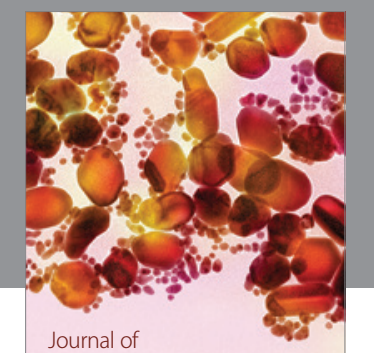

Soft Matter
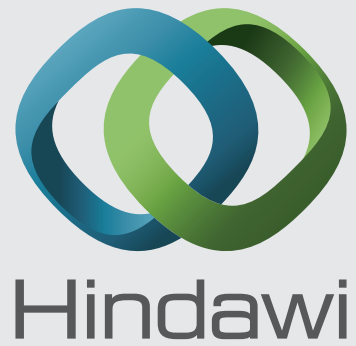

Submit your manuscripts at

http://www.hindawi.com
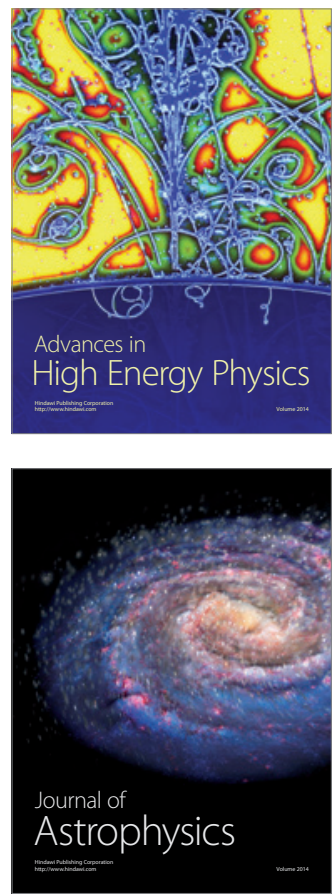
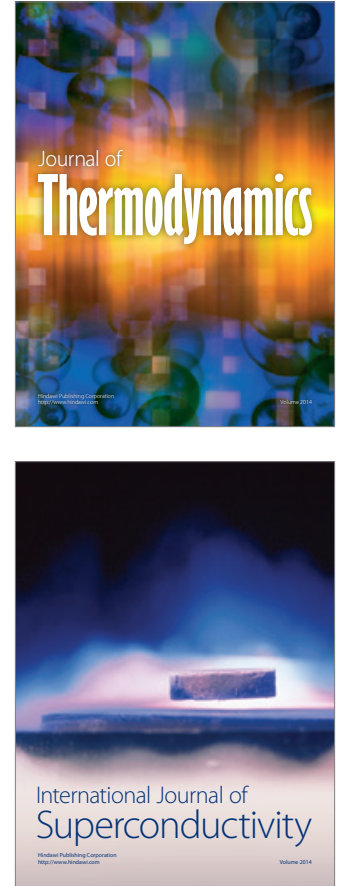
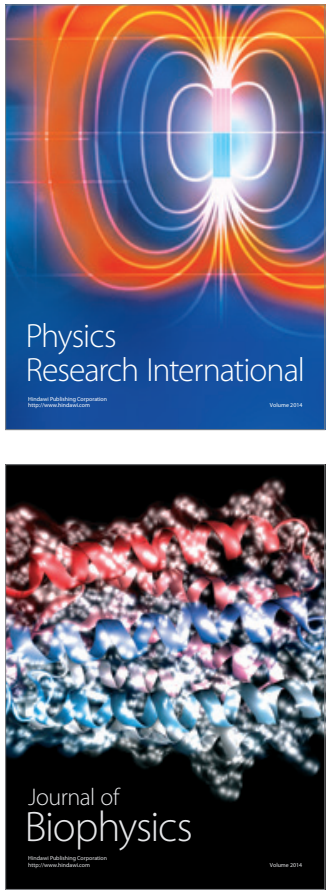
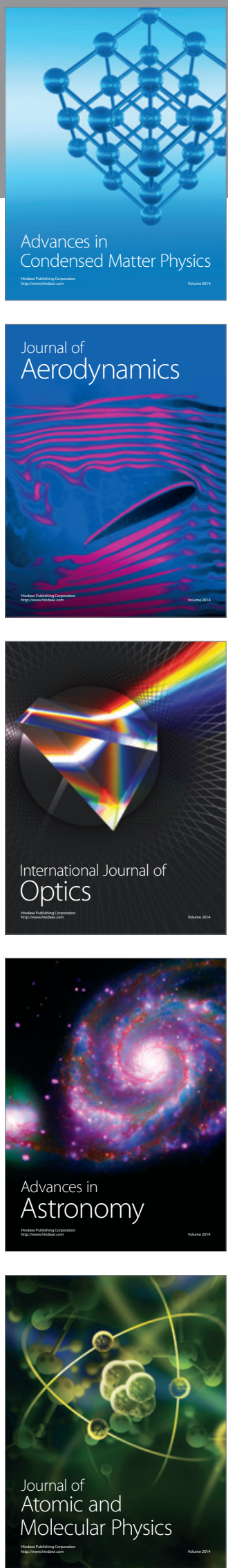